which is unique among the Arthropoda.

Furthermore, studies of larval development, growth, sex determination and genetics have all pushed forward in recent years, not least in relation to the growing importance of crustaceans in aquaculture. Also, new and important studies on the neurobiology of crustaceans are concerned with the investigation of single identifiable neurons, ultrastructure and function in synapses, and the modulatory role of neurohormones on the nervous system and on behaviour.

As a reference source for these and other developments in the phylogeny, genetics, morphogenesis and neurobiology of crustaceans, the first three volumes of The Biology of Crustacea will no doubt be a success. These, and the later volumes in this ambitious series, are in the hands of an impressive array of authors and editors, and the whole project should contribute greatly to the further advancement of carcinology.

However, some problems of this compendium approach to book writing are already evident, and the problems seem likely to increase as later volumes appear. In some areas there is contrived compartmentalization and in others there is overlap and often conflict. Somewhat arbitrary subdivisions come through, for example in the chapter on evolution within the Crustacea (Vol.1) which is divided into four parts (General, Copepoda, Cirripedia and Ostracoda) each written by a different author. In Vol. $\mathbf{2}$ where it is rightly argued that it is difficult to separate structure from function, the chapter on comparative morphology of crustacean appendages ignores function because that is discussed by several other authors in several other chapters in several other volumes.

The more circumscribed chapters are good and, in general, seminal, but the overlap of topics between several of the contributions often no more than reflects the controversies in the primary literature without synthesizing and developing the arguments. In Vol. 1, for example, important topics such as the origin of the Crustacea and the phylogenetic position of the Cephalocarida extend over several chapters in an uncoordinated manner. Indeed, the essence of the problem of a series of books on a topic such as this, written and edited by so many people, is crystallized in the reluctance of the editors at the outset to conclude whether the Crustacea are a Phylum, a Subphylum or a Superclass. One would like to have seen here and elsewhere the formulation of more hypotheses, albeit in the spirit of the quotation by R. W. Burkhardt referred to in Vol. 1, that "He [Lamarck] had little patience with those who did not realize that a theory could be founded upon a great number of facts and still be false"'.

E. Naylor is Lloyd Roberts Professor of Zoology at the University College of North Wales, Bangor.

\section{Do-it-yourself in the laboratory}

\section{A. Elliott}

Building Scientific Apparatus:

A Practical Guide to Design and Construction.

By John H. Moore, Christopher C. Davis and Michael A. Coplan.

Addison-Wesley: 1983. Pp.483. $\$ 54.95$, £41.20.

THE SCOPE of Building Scientific Apparatus is wider than the title suggests, in that the book contains much basic theory underlying the design of physical instruments. The authors have endeavoured to provide the knowledge needed to design instruments, to communicate with the technicians in workshops or the firms who will construct them, and to inform the reader where ready-made components can be obtained. Readers in the United States will benefit most from this last feature, for American sources far outweigh all others. Similarly, inches and pounds are used as well as metric units, which reflects American practice. The text is well supported by numerous general and cited references.

The authors start with brief accounts of mechanical design (which show the reader how to prepare working drawings) and of laboratory glass-working. The following, very useful chapter on vacuum technology adequately covers the subjects of gas flow and pressure measurement. A section on pumps includes details of sorption, getter, cryo and ion pumps, and the chapter ends with a practical section on vacuum system design and construction.

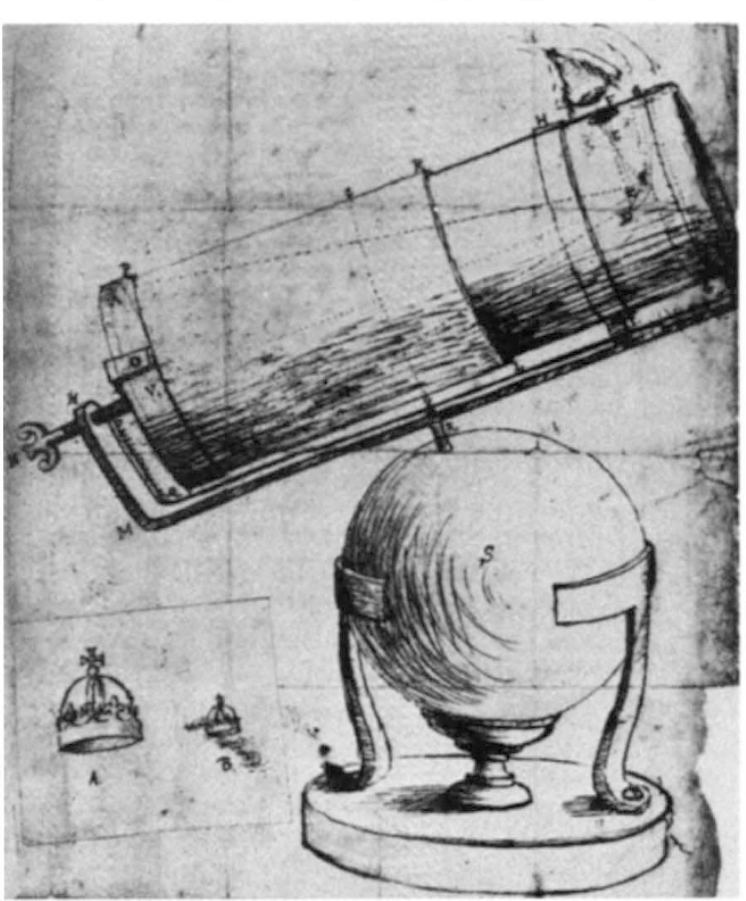

HOME-made in the seventeenth century - a reflecting telescope built by Isaac Newton in 16681669. When drawn to the attention of the "eminent grandees" of the Royal Society in 1671 , it gained recognition for Newton who then "stepped publicly into the community of natural philosophers to which he had hitherto belonged in secret".

The illustration and quotation are taken from Richard S. Westfall's well received biography of Newton, Never at Rest, which has been issued in paperback by Cambridge University Press (price $£ 12.50$, $\$ 19.95)$. For review see Nature 290, 803; 1981.

Also newly available in paperback is The Newtonian Revolution, with Illustrations of the Transformation of Scientific Ideas by I. Bernard Cohen. The book was reviewed in Nature 292, 392; 1981. Publisher is again Cambridge University Press; price is $\mathbf{\AA 9 . 9 5 , \$ 1 6 . 9 5}$. 